\title{
ON THE LEAKAGE CURRENT MECHANISM IN NON-UNIFORM FILM POLYCRYSTALLINE SILICON TFTS
}

\author{
Anish Kumar K.P.. Johnny K.O. Sin, and Hoi S. Kwok \\ Center for Display Research, Department of Electrical and Electronic Engineering \\ The Hong Kong University of Science and Technology \\ Clear Water Bav, Hong Kong
}

\begin{abstract}
Leakage current mechanism in polysilicon TFTs fabricated on a non-uniform film is investigated. The approach utilizes test structures which have non-uniform film thickness at the drain, source and channel regions. An order of magnitude reduction in leakage current at high drain bias is observed in the thick drain TFT structure compared to the thin drain structure. The improvement on the leakage current is due to the reduction in electric field at the thicker drin. The electric field reduction in the thick drain structure is verified using two-dimensional simulations. The influence of the electric field on the anomalous leakage current is investigated with the grain boundary trapping effects separated out.
\end{abstract}

\section{INTRODUCTION}

Polysilicon thin filu transistors (TFT's) fabricated using a low temperature process have gained much attention in flat paud display such as AMI,(1)s. 'TF'I devioes made with thinmer film have the advantages of lower grain boundary trap density, higher mobility, and higher on-state current compared to thicker film devices [1]. However, thinner film devices experience higher electric field due to two dimensional effect arises from the reduced junction depth compared to thicker film devices $[2,3]$. The anomalous leakage current in TFT's is a function of channel electric field and number of grain boundary traps in the polysilicon film. In fact. the leakage current is exponentially dependent on the electric field and just directly proportional to the grain boundary trap density [4]. In order to roduce this electric ficld, a lightly doped drain (LIJI)) structure or offset-drain structure is usually employed $[5,6]$. However, these structures introduce high source/drain series resistance which limits the on-state current. It was reported freviously that the electri. fiell can be reduced in thin film SOI MOSFETs by using a thick drain structure, resulting in higher breakdown voltage [3]. However, no previous work has been reported on the effect of the thick drain structure on the leakage current in TF'] devices.
In this work, the source, channel and drain thicknesses of the polysilicon TFTs are varied using chemomechanical polishing of the active film. These structures are used to study the leakage current mechanism and its dependence on drain electric field without the influence of grain boundary trapping effects. Experimental results show that a significant reduction in leakage current in the thick drain structure is obtained compared to the thin drain structure. Furthermore, using this approach, the effect of the channel clectric fiek on the leakage current can be studied without the influence of grain boundary trapping effects.

\section{Device Fabrication}

Schematic cross-section of the test structures with different source, drain and channel region thicknesses are shown in Fig. 1. The three test structures fabricated are 1) structure with the source and the channel region made on thicker film $(3000 \AA)$ and drain region mate on thinner film ( $800 \AA$ ), 'Type-A, 2) structure with the drain and the channel region made on thicker film and the source region made on thinner film, TypeB, and 3) structure with the source and the channel region made on thinner film and the drain region made on thicker film, Type-C. The process steps for the fabrication of these structures are described as follows.

Schematic cross-section of the process steps are shown in Fig. 2. Silicon wafers with $5000 \AA$ thermally grown oxide were used as starting substrates. A $2000 \AA$ polycrystalline silicon was deposited first and patterned. Subsequently, a $1000 \AA$ LPCVD oxide was deposited. Following that, a $5000 \AA$ silicon layer wais deposited at $550^{\circ} \mathrm{C}$ in amorphous form by L.PCVD. The amorphous silicon was then recrystallized for 20 hours in nitrogen ambient at $600^{\circ} \mathrm{C}$. After the island formation (Fig. $2 \mathrm{a}$ ), a $3000 \AA$ LTO was deposited and patterned using the negative of the island mask (Fig, 2b). This oxide will be used as polish stop for achieving the various film thicknesses. The wafer was then chemo-mechanically polished up to the LTO polish stop as shown in Fig. 2c. Due to the excellent selectivity between polysilicon and LTO dur- 


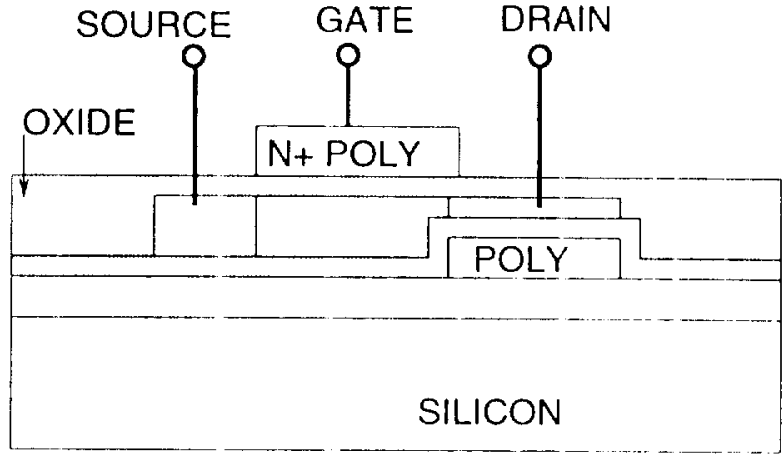

(A)

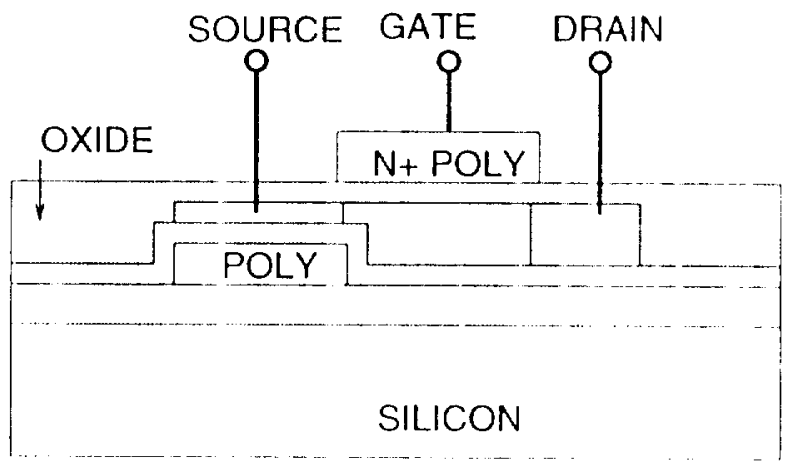

(B)

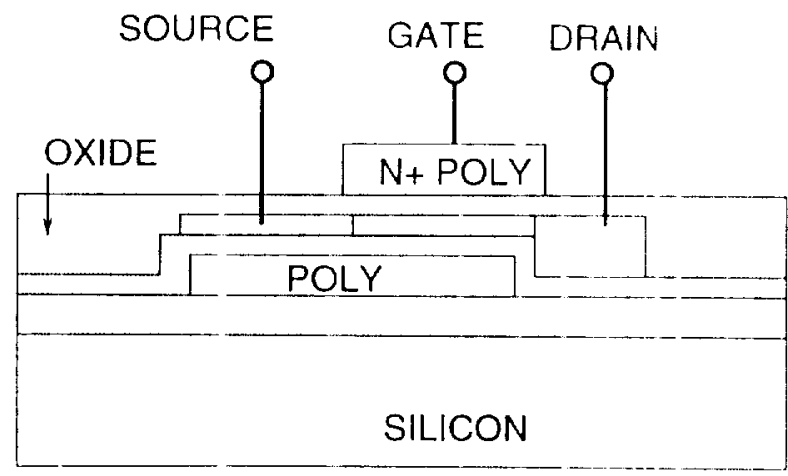

(C)

Fig. 1. Schematic cross-section of the test structures: (a) thick source and channel region, Type- $A$, (b) thick drain and channel region, Type-B, and (c) thin source and channel region, Type- $C$ (thicknesses for the thick and thin regions are $3000 \AA$ and $800 \AA$, respectively). ing polishing, a very good control on the thickness of the polysilicon is achieved. After polishing, polysil ien regions with different thicknesses $(\sim 800$ : 1 and $\sim 3000 \mathrm{i})$ are formed in the various regions of $1 / \mathrm{t}$. devices. The surface topology becomes flat all over the wafer after the polishing. Furthermore, an 1000.t $\Lambda I^{\prime}(Y D)$ oxide was deposited as front gate oxide, and : 2500.1 gate polysilicon was deposited and pattermed. A self-aligned $\mathrm{N}+$ implantation was then performol (Fig. 2(1). 'The dopants were activated during lensification of the L'IO at $600^{\circ} \mathrm{C}$ for 10 hours in exygen ambient. After the metallization and patterning, the devices were hydrogenated using; H, r.f. plasmit for? liours.

\section{RESUITS AND DISCUSSION}

for an I.P'('VD) polysilicon 'lly'l, according to the

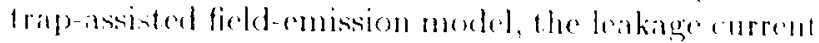
(a) lo expressed ats [ 11$]$

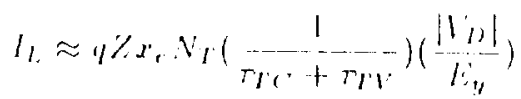

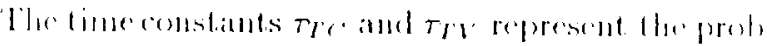
ability fer tonst time that at trapeded carrier will tou

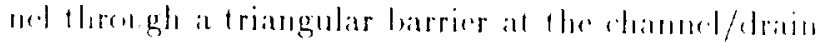
imedien. They can be expressond as

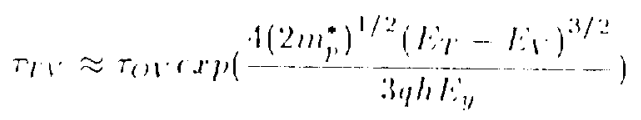

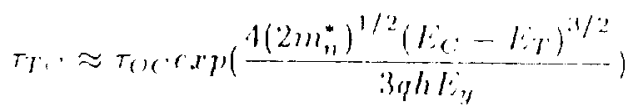

where mo, and mo are the efferdive mass for holes and lectrons. $\tau_{01}$ and $\tau_{O C}$ are the elfective carrier transit tinc in the valenee and conduction bands. $E_{y}$ is the

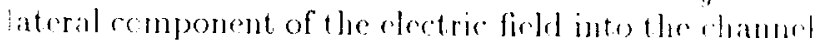
from the drain, $x_{e}$ is the effoctive depthe of the jume tion region, $E_{T}$ is the triangular barrier loright at the hannd/Arain junction, $N_{T}$ is the trap density which is rqual to $2 \mathrm{~N}_{S T} / \mathrm{d}_{G}$ where $\mathrm{N}_{S T}$ is the grain loundury arcal trap density and $\mathrm{d}_{G}$ is the average colummar srain size. It is seen from the above equation that the leakage current is exponentially dependent on the itrength of the electric field. Therefore, the loakage surront can be reduced by decreasing the electrie field th the channel/drain junction.

Fig. 3 illustrates the gate characteristics of lype-A and 'Type-l3 devices with identical device dimcnsions and drain voltage. It is seen that the leakage current of 'Type- 3 devices at the zero gate bias and in the negative gate bias regime is remarkably lower than 1.hat of 'Type-A devices. This reduction in the lokage? :urrent is due to the reduction of the electric field :n Type-B devices since its drain junction depth is: ncrased compared to that of Type-A devices. It is 


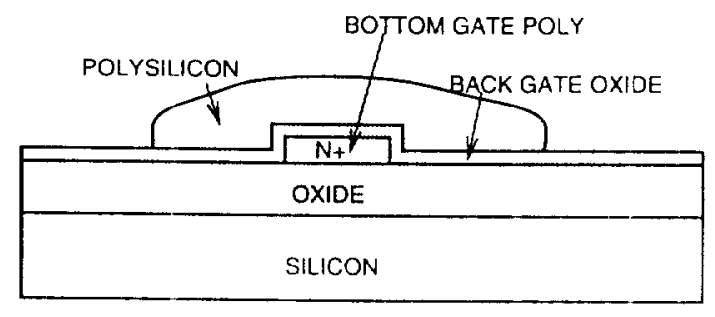

(a)

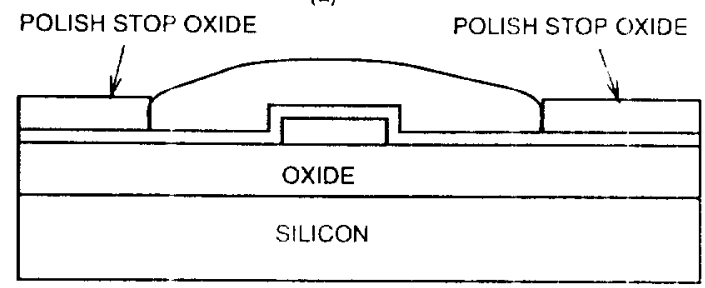

(b)

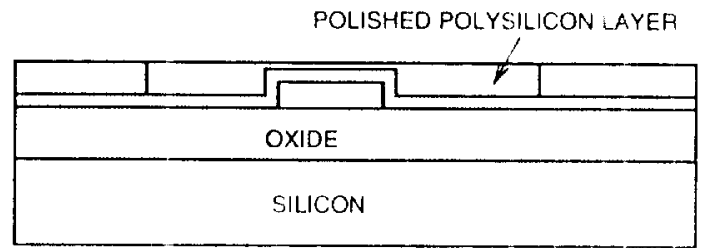

(c)

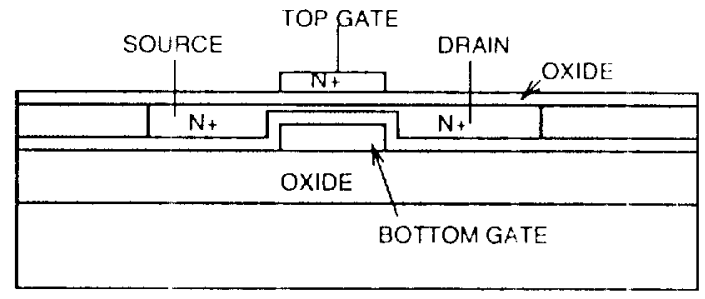

(d)

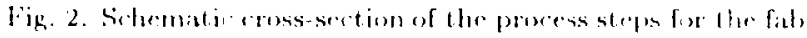

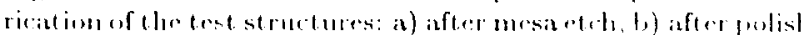

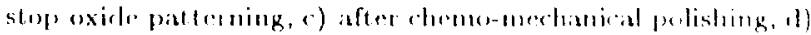
after gate patterning and source/drato implantation

also seen from fig. 3 that the on-state current of Type-A devices is slightly higher than that of 'lype$B$ devices. This is because hot carriers are generated due to the high electric field in Type-A deries tho minimum leakage current is decreased more than an order of magnitude in Type-B devices in comparison to 'Type-A devices. This reduction in leatages current improves the en/off current ratio of lype-B devices.

Fig. 4 shows the simulated lateral clectric field profile at the channel/drain junction of 'Tye- $A$ and Type-13 (thin and thick drain) devices whon the de vices were biated at $V_{D S}=5 \mathrm{~V}$ and $V_{G S}=-5 \mathrm{~V}$. A $15 \%$ reduction in lateral electric field is oblained in thick drain (Type-13) devices.

Fig. 5 shows the gate transfer characteristics of Type-13 and ' I'ype-C devices. 'Type-B and 'Type-c devices are the same except that the channel region in Type-C devices is thimer. Both structures atre main

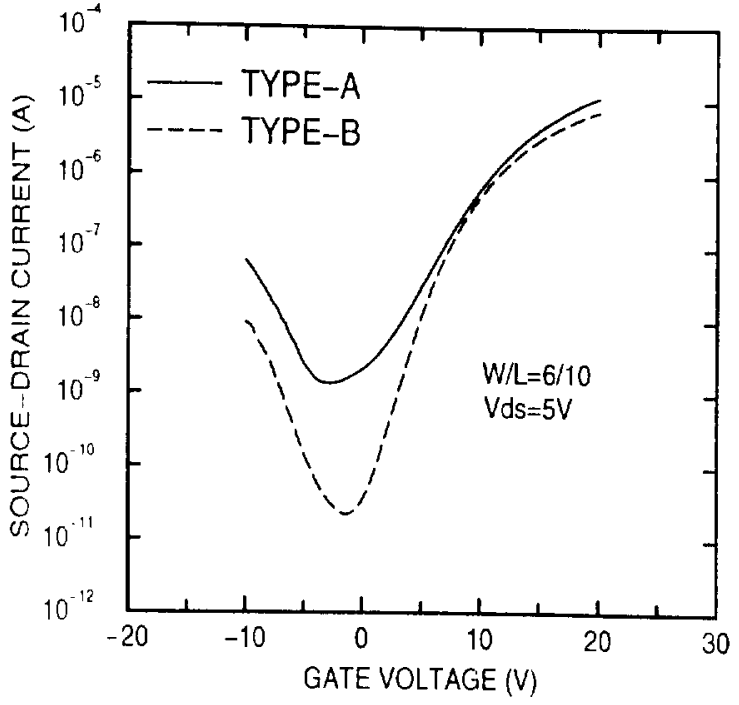

lig. :3 Ciate transfer characteristice of Type-A and Type-1 leviles.

tained with a thick drain region. In doing so, the num ber af grain boumdary traps in the channel region a

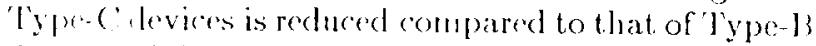
devires while still mantainimg the same rectric field from lig. 5, it is shown that the zero bias leakige cur rent is not clependent on the number of grain bound ary trape. Jowever, the anomalous leakige current in the negative gate hias regine is strongly dependent on the mumber of grain boumdary traps. Comparing Fig 3 and lig. 5, one can sec that the zero bias leakagi rurrent is more strongly dependent on the stremgth of the olectric field at the channel/drain region than on the mumber of grain boundary traps.

It is atso important to note that in thinner film de viess, the higher electric lield will generate more hot carriers which cventually causes kink effect to occur 'lherefore, a thin channel region with a thick source. and dran regions can give a higher on/off currenl ratio and at the same time provide reduced kink of fect. In addition, for sub-micron devices, it providen lower source/drain series resistance due to the thick source/drain region.

\section{CONCLUSION}

Unique test structures were fabricated to analyz. the dependence of the leakage current on the electric field. Using these structures, it was experimentally demonstrated that the anomalous leakage current was increased with increasing electric field. It was found that by thickening the drain region, the strength of the wectric field at the drain/channel region is reduced. and thereby reducing the leakage current. Simulation results have also verified that the electric field at the 


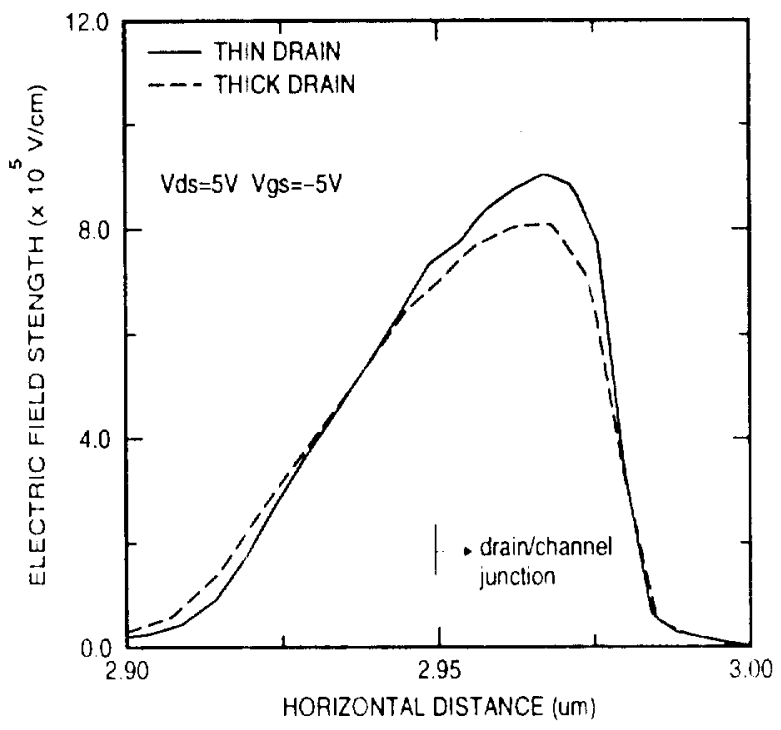

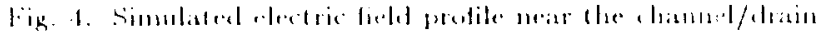

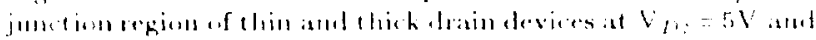
$V_{1}+2=5 V$.

Anamel/drain junction region is indeed ralued. Wo have also investigated the eflect of the electrie field an the leakage enrent withoul the influene of the gram benmelary trap charges in the chammel region.

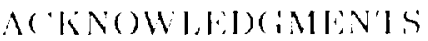

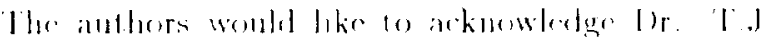

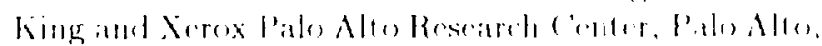
for theje gemerous help in performing the plassola hydrogenation. 'This work was supportert hy the Rec'

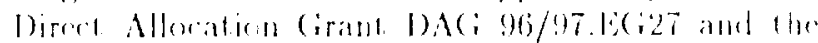
(enter for Display Researeth, the Industral Suppert Funcl, llong Kolg (iovernment Industry l)eputment.

\section{REFERENCES}

[1] M. Miyasaka, 'T. Komatsu, W. Itoh, I Yam aguchi and H. Ohashima, "Effects of Chanmel Thickness on Poly-Crystalline Silicon 'Thin Yilm 'Transistors", Extended Abstracts of Sis') 11, Osaka, Japan, pp. 647-650, 1995.

[2] S. Yamada, S. Yokoyama and M. Koyanagi, "Two-Dimensional Device Simulation for Avalanche Induced Short Channel Effect in PolySi TFT". IEDM Tich. Digest, pp. 859-86', 1990)

[3] M. Yoshimi, M. Takahashi, T. Wara, K. Kato S. Kambayashi, M. Kemmochi and K Vatori, "Analysis of the Drain Breakdown Mechanism in Ultra-Thin. Film SOI MOSEET"s", LEEE Thans. Electron Dev., Vol. 37, No. 9, pp. 2015-2021, 1990

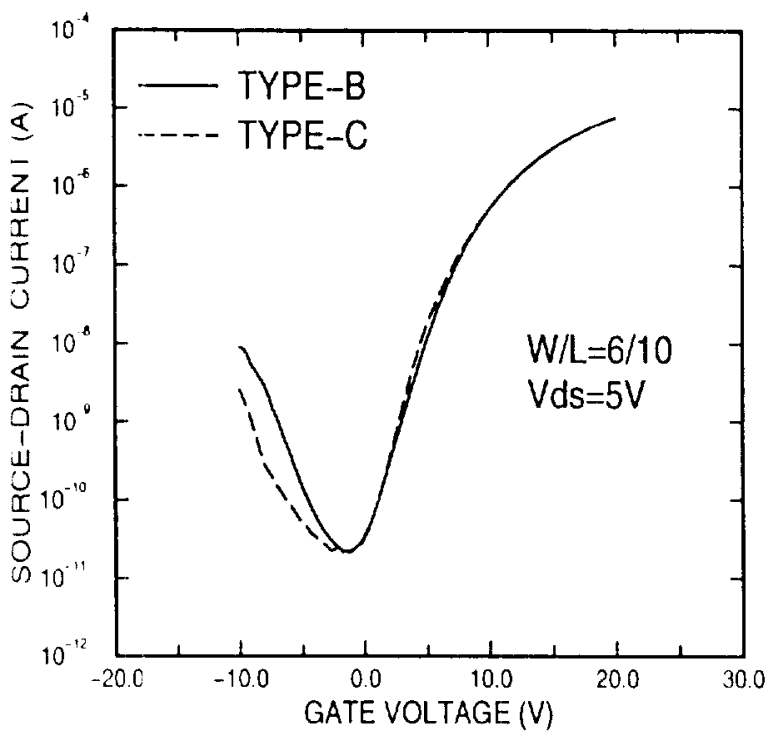

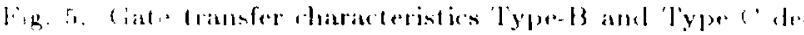
vi in

1] J r fossmm, A. Ortiz-( omelo, H. Shlochijo ame

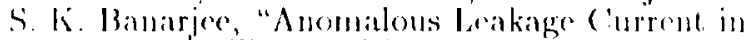

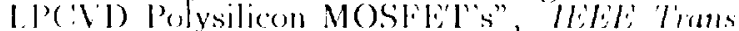

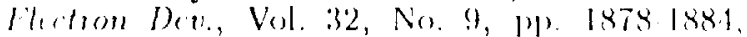
$19 \times 5$

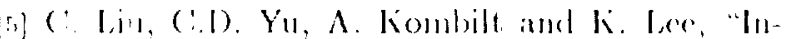
vered Thin Filn Transistors with a Simple Self-

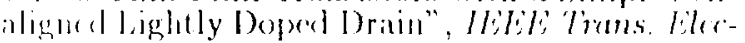

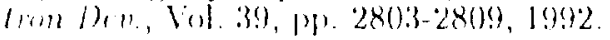

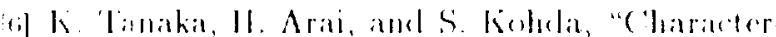

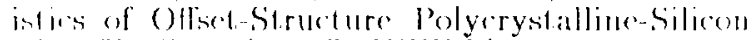

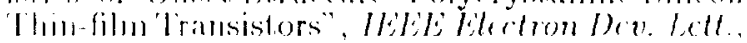
V1.? No.1. 19. 23-25, 1988. 